\title{
KEPATUHAN TENAGA KERJA DALAM MENGGUNAKAN APD DI TEMPAT KERJA
}

\author{
Fety 'Izza Luthfiyah \\ Departemen Keselamatan dan Kesehatan Kerja \\ Fakultas Kesehatan Masyarakat, Universitas Airlangga \\ Email: fety.izza@gmail.com
}

\begin{abstract}
Workers when at working area must use (Personal Protective Equipment) PPE, even though the company has implemented technical controls and administrative controls. But, use of PPE at work is still not good. The purpose of this study was to analyse the compliance of workers in using PPE in production department of PT X. this study was an descriptive observational study with a cross sectional study design. The total study population was 30 people with total sampling. Data were by means as of questionnaire. The result of the study were the average age and length of work of workers in production department of PT X were $\mu=29,47 \pm 4,99$ years old and $\mu=7,9 \pm 3,96$ years. Workers in production department of PT X 60\% use PPE and 40\% not use PPE. The factor that influence compliance with PPE use was comfort of PPE and factors that don't affect compliance with PPE use were availability of PPE, PPE training, and supervision of PPE. It is recommended for the company need to approach individually to the workers and need to implement a reward policy.
\end{abstract}

Keywords: Compliance, PPE, Worker, Factors

\begin{abstract}
ABSTRAK
Tenaga kerja selama bekerja tetap diharuskan untuk memakai APD, meskipun perusahaan telah menerapkan pengendalian secara teknik dan administratif. Akan tetapi penggunaan APD di tempat kerja masih belum baik. Tujuan dari penelitian ini adalah menganalisis kepatuhan tenaga kerja dalam menggunakan APD di departemen produksi PT $\mathrm{X}$. Penelitian ini merupakan penelitian deskriptif observasional dengan rancang studi cross sectional. Total populasi penelitian sebesar 30 orang dengan pengambilan sample menggunakan total sampling. Pengumpulan data dengan menggunakan kuesioner. Hasil penelitian di dapatkan bahwa rata-rata umur dan masa kerja tenaga kerja di departemen produksi PT $X$ masing-masing adalah $\mu=29,47 \pm 4,99$ tahun dan $\mu=7,9 \pm 3,96$ tahun. Tenaga kerja di departemen produksi PT X 60\% menggunakan APD dan $40 \%$ tidak menggunakan APD. Faktor yang mempengaruhi kepatuhan penggunaan APD adalah kenyamanan APD. Faktor yang tidak mempengaruhi kepatuhan penggunaan APD tenaga kerja di departemen produksi PT X adalah kesediaan APD, pelatihan APD, dan pengawasan APD. Saran yang dapat diberikan pada penelitian ini adalah perusahaan perlu melakukan pendekatan secara individual kepada tenaga kerja dan perlu menerapkan kebijakan reward.
\end{abstract}

Kata kunci: Kepatuhan, APD, Tenaga Kerja, Faktor 


\section{PENDAHULUAN}

Kejadian kecelakaan kerja di Indonesia dari tahun ke tahun mengalami peningkatan. Pada tahun 2017, total kecelakaan kerja yang terjadi sebanyak 123 ribu kasus dengan total klaim negara mencapai lebih dari Rp 971 miliar. Kejadian kasus kecelakaan kerja tersebut meningkat $20 \%$ dari kejadian kasus kecelakaan kerja tahun 2016. Semakin meningkatnya kejadian kecelakaan kerja disebabkan karena kurangnya komitmen perusahaan dalam penerapan $\mathrm{K} 3$ di tempat kerja.

Untuk mengendalikan agar kecelakaan kerja tidak terjadi, dapat dilakukan dengan cara menerapkan hirarki pengendalian, yang meliputi pengendalian teknik, pengendalian administratif, dan Alat Pelindung Diri (APD). ${ }^{1}$ Walaupun APD merupakan garis pertahanan terakhir (the last line of defence), namun pada pelaksanaannya untuk setiap tenaga kerja yang bekerja diharuskan memakai APD meskipun pengendalian teknik dan pengendalian secara administratif telah diterapkan. Hal ini dikarenakan bahaya di tempat kerja tidak bisa dihilangkan meskipun perusahaan telah melakukan pengendalian teknik dan pengendalian secara administratif untuk mengendalikan kecelakaan kerja. Penggunaan APD tersebut diterapkan bukan sebagai mencegah terjadinya kejadinya kecelakaan kerja, namun untuk mengurangi tingkat keparahan dan cedera apabila kecelakaan kerja terjadi.
Tingkat kepatuhan penggunaan APD di tempat kerja masih belum baik. Menurut Nugroho (2015), pada pekerjaan bidang konstruksi ditemukan sebanyak 56,5\% tenaga kerja konstruksi tidak patuh untuk menggunakan APD ketika bekerja. ${ }^{2}$ Sedangkan menurut Iqbal (2014), pada pekerjaan bidang manufaktur, tenaga kerja yang tidak patuh menggunakan APD sebanyak 94\% tenaga kerja $^{3}$ dan menurut Lagata (2015), sebanyak $35,6 \%$ tenaga kerja bagian produksi di industri manufaktur tingkat kepatuhan dalam menggunakan APD kurang. ${ }^{4}$ Tingkat kepatuhan penggunaan APD oleh tenaga kerja tersebut dipengaruhi oleh beberapa faktor. Menurut Arifin (2013), tenaga kerja tidak patuh menggunakan APD dikarenakan APD tidak nyaman digunakan. ${ }^{5}$ Sedangkan menurut Lathif (2015), tenaga kerja yang pernah mendapatkan pelatihan mengenai APD lebih patuh dalam menggunakan APD saat bekerja. ${ }^{6}$ Menurut Dhani (2015), pengawasan yang rutin dilakukan oleh perusahaan memicu tenaga kerja untuk berperilaku patuh dalam menggunakan APD. ${ }^{7}$

PT X merupakan industri kimia yang memproduksi minyak putih. Bahan baku dan proses produksi yang ada di PT X memiliki risiko bahaya yang tinggi. Bahan baku yang digunakan adalah gas alam yang memiliki sifat kimia berbahaya. Sedangkan, proses produksinya menggunakan suhu dan tekanan yang tinggi serta menggunakan aliran steam 
dan listrik. Kecelakaan kerja yang terjadi di PT $\mathrm{X}$ sebagian besar disebabkan oleh unsafe act. Unsafe act yang paling banyak dilakukan oleh tenaga kerja di PT X adalah kelalaian dalam menggunakan APD. Berdasarkan studi pendahuluan didapatkan bahwa terdapat beberapa perilaku kurang aman yang dilakukan oleh tenaga kerja di PT X, seperti tidak menggunakan APD, bercanda dengan rekan kerja saat bekerja, dan bekerja secara tidak ergonomis.

Perilaku tenaga kerja yang lalai tidak menggunakan APD tersebut jika terjadi secara terus menerus maka berisiko menimbulkan kecelakaan kerja yang lebih serius. Maka penelitian ini bertujuan untuk menganalisis kepatuhan tenaga kerja dalam menggunakan APD di departemen produksi PT X.

\section{METODE PENELITIAN}

Jenis penelitian ini merupakan deskriptif observasional karena variabel yang diteliti tidak diberikan perlakuan dan dianalisis secara deskriptif untuk melihat gambaran kepatuhan tenaga kerja dalam menggunakan APD di departemen produsi PT X. Rancang bangun penelitian ini adalah cross sectional karena data yang diteliti diamati dalam satu waktu. Populasi penelitian ini adalah seluruh tenaga kerja di departemen produksi PT X yang berjumlah 30 orang. Penentuan sampling pada penelitian ini yaitu menggunakan total sampling. Variabel yang teliti berupa variabel indenpenden (umur, masa kerja, ketersediaan APD, kenyamanan APD, pelatihan APD, dan pengawasan APD) dan variabel dependen (penggunaan APD). Cara pengumpulan data melalui wawancara dengan panduan kuesioner. Data yang didapat kemudian dianalisis secara deskriptif untuk melihat gambaran kepatuhan penggunan APD.

\section{HASIL DAN PEMBAHASAN}

\section{Gambaran Karakteristik Tenaga Kerja}

Tabel 1. Distribusi Frekuensi Karakteristik Tenaga Kerja di Departemen Produksi PT X.

\begin{tabular}{lcc}
\hline \multicolumn{1}{c}{ Karakteristik } & f & \% \\
\hline Umur & & \\
$21-29$ tahun & 14 & 46,67 \\
$30-38$ tahun & 16 & 53,33 \\
\hline Jumlah & 30 & 100 \\
\hline Masa Kerja & & \\
$2-7$ tahun & 13 & 43,33 \\
$8-13$ tahun & 17 & 56,67 \\
\hline Jumlah & 30 & 100 \\
\hline
\end{tabular}

Berdasarkan Tabel 1, dapat diketahui bahwa sebagian besar tenaga kerja di departemen produksi PT X berumur $30-38$ tahun dan memiliki masa kerja $8-13$ tahun. Umur tenaga kerja termuda dan tertua masingmasing adalah 21 tahun dan 38 tahun. Sedangkan, masa kerja tenaga kerja tersingkat dan terlama masing-masing adalah dua tahun dan 13 tahun. Rata-rata umur tenaga kerja di departemen produksi PT X adalah $\mu=29,47 \pm$ 4,99 tahun dengan median 30 tahun. Sedangkan, rata-rata masa kerja tenaga kerja di departemen produksi PT $\mathrm{X}$ adalah $\mu=7,9 \pm$ 3,96 tahun dengan median 12,27 tahun. 


\section{Tingkat Kepatuhan Penggunaan APD}

Tabel 2. Distribusi Frekuensi Penggunaan APD pada Tenaga Kerja di Departemen Produksi PT X.

\begin{tabular}{lcc}
\hline \multicolumn{1}{c}{ PenggunaanAPD } & $\mathrm{f}$ & $\mathbf{\%}$ \\
\hline Selalu & 18 & 60 \\
Kadang-kadang & 12 & 40 \\
\hline Jumlah & 30 & 100 \\
\hline
\end{tabular}

Penilaian kepatuhan penggunaan APD pada tenaga kerja di departemen produksi PT X dinilai berdasarkan kelengkapan dan penggunaan APD yang tepat. Berdasarkan Tabel 2, dapat diketahui bahwa sebanyak $60 \%$ tenaga kerja selalu menggunakan APD. Tenaga kerja tersebut sadar bahwa terdapat risiko yang dapat membahayakannya sehingga tenaga kerja mencegahnya dengan menggunakan APD selama bekerja. Akan tetapi, masih terlihat tenaga kerja yang tidak memakai APD sebanyak 40\%. Tenaga kerja tersebut tidak memperdulikan adanya risiko yang ada selama bekerja sehingga memilih untuk tidak menggunakan APD. Berdasarkan hasil observasi, APD yang paling banyak tidak digunakan oleh tenaga kerja adalah sarung tangan dan masker.

PT X telah menyediakan APD secara cuma-cuma kepada tenaga kerja dan jumlahnya telah disesuaikan dengan jumlah tenaga kerja. APD yang disediakan juga telah memenuhi standard minimal yang berlaku yaitu APD yang disediakan disesuaikan dengan risiko yang ada di tempat kerja dan ukuran APD yang disediakan disesuaikan dengan ukuran fisiologis tenaga kerja. Pengorganisasi terkait persediaan APD telah dilakukan secara baik oleh PT X. Setiap tahun PT X memiliki anggaran untuk pembelian APD yang disesuaikan dengan kebutuhan tenaga kerja di masing-masing pekerjaan dan PT $X$ telah menentukan pemberian APD kepada tenaga kerja tersebut serta jangka waktu penggunaannya. Sehingga, ketersediaan APD di PT X mudah di dapatkan oleh tenaga kerja dan cukup untuk kebutuhan tenaga kerja. Akan tetapi, PT X menyerahkan kepada masingmasing tenaga kerja mengenai perawatan dan pemeliharaan APD yang telah diberikan perusahaan dengan disediakannya loker kepada masing-masing tenaga kerja untuk digunakan sebagai tempat menyimpan APD. Apabila APD rusak sebelum jangka waktunya, tenaga kerja dapat meminta ganti dengan menunjukkan bahwa APD tersebut memang benar rusak dan perlu diganti. Hal ini telah sesuai dengan Peraturan Menteri Tenaga Kerja Transmigrasi RI No. 8 Tahun 2010 tentang Alat Pelindung Diri yang menyatakan bahwa perusahaan wajib menyediakan APD bagi tenaga kerja di tempat kerja yang harus disesuaikan dengan standar yang berlaku serta diberikan secara cumacuma. Sehingga dapat dikatakan bahwa PT X telah mengupayakan dan melaksanakan kewajibannya dalam memenuhi kebutuhan tenaga kerja terkait ketersediaan APD.

Menurut Notoatmodjo (2003), ketersediaan merupakan salah satu faktor yang 
mempengaruhi perilaku seseorang. ${ }^{8}$ Akan tetapi, masih terlihat adanya tenaga kerja yang tidak patuh untuk menggunakan APD selama bekerja. Sehingga ketersediaan APD di PT X tidak mempengaruhi penggunaan APD tenaga kerja di departemen produksi PT X. Hal ini sejalan dengan penelitian yang dilakukan Sulistyaningsih (2015) yang mengatakan bahwa meskipun perusahaan menyediakan APD secara cuma-cuma namun tenaga kerja tetap tidak menggunakan APD. Hal ini disebabkan karena kurangnya kesadaran tenaga kerja mengenai pentingnya penggunaan APD. ${ }^{9}$

Tenaga kerja di departemen produksi PT $\mathrm{X}$ paling jarang menggunakan APD sarung tangan dan masker. Hal ini dikarenakan faktor kenyamanan APD tersebut. Berdasarkan hasil wawancara, tenaga kerja mengatakan bahwa sarung tangan dapat menghambat pergerakan jari tenaga kerja. Apabila tenaga kerja memakai sarung tangan, tenaga kerja merasa tidak bisa leluasa ketika bekerja dan merasa gerah. Sama halnya ketika menggunakan masker, tenaga kerja merasa sulit untuk bernafas dengan lancar. Selain itu, berdasarkan hasil wawancara, didapatkan bahwa terdapat keluhan tenaga kerja mengenai penggunaan APD yang bertumpuk dan ukurannya tidak sesuai dengan tubuh tenaga kerja. Padahal menurut Syaaf (2008), kenyamanan akan timbul apabila seseorang membiasakan diri melakukan sesuatu hal. ${ }^{10}$

Sedangkan, menurut De Reanner, APD harus mempunyai persyaratan tidak menggang- gu kerja yang berarti bahwa APD harus sesuai baik ukuran maupun karakteristik tubuh pemakainya dan tidak menyulitkan gerak pengguna serta memberikan perlindungan efektif terhadap jenis bahaya yang khusus sebagaimana APD tersebut di desain. ${ }^{11}$ Sehingga, kenyamanan APD mempengaruhi penggunaan APD tenaga kerja di departemen produksi PT X. kondisi demikian tidak sesuai dengan penelitian yang dilakukan Nugroho (2015) yang menyatakan bahwa kenyamanan APD pada tenaga kerja tidak berhubungan dengan penggunaan APD. ${ }^{2}$

PT $X$ telah mengadakan pelatihan mengenai penggunaan APD kepada tenaga kerja. Pelatihan tersebut telah terjadwal dan terstruktur yang dilakukan setiap enam bulan sekali dan diadakan secara bergantian kepada setiap tenaga kerja. Materi pelatihan disampaikan oleh pihak K3 PT X mengenai potensi bahaya dan jenis APD yang digunakan, pentingnya menggunakan APD, dan cara menggunakan APD dengan benar. Pelatihan merupakan salah satu bentuk pembinaan terhadap tenaga kerja yang diupayakan untuk membuat tenaga kerja patuh dalam menggunakan APD. Pelatihan APD di PT X telah sesuai dengan Peraturan Pemerintah No. 50 Tahun 2012 tentang Penerapan SMK3 dan Undang-undang No. 1 Tahun 1970 Pasal 9 yang menyatakan bahwa perusahaan wajib menyelenggarakan pembinaan bagi tenaga kerja dalam pencegahan kecelakaan. ${ }^{12,13}$ Akan 
tetapi masih terlihat adanya tenaga kerja yang tidak patuh untuk menggunakan APD selama bekerja. Sehingga, pelatihan APD tidak mempengaruhi penggunaan APD tenaga kerja di departemen produksi PT X. Hasil penelitian ini sejalan dengan penelitian yang dilakukan oleh Sulistyaningsih (2015) yang menyatakan bahwa meskipun pelatihan mengenai APD telah dilakukan namun tenaga kerja tetap tidak menggunakan APD. Sehingga walaupun tenaga kerja telah mengikuti pelatihan, akan tetapi tenaga kerja tidak mempraktikkan ilmu yang didapatkan saat pelatihan. ${ }^{9}$

PT X melakukan pengawasan penggunaan APD secara rutin setiap hari yang dilakukan oleh pihak K3, bagaian keamanan, dan supervisor departemen. Hal ini sesuai dengan Peraturan Pemerintah No. 50 Tahun 2012 tentang Penerapan SMK3 klausul 6.2 yang menyatakan bahwa perusahaan melaksanakan pengawasan untuk menjamin setiap pekerjaan dilaksanakan dengan aman dan mengikuti prosedur serta petunjuk keja yang telah ditentukan. $^{12}$ Pengawasan penggunaan APD telah dilakukan pada tenaga kerja di departemen produksi PT X, tetapi tenaga kerja masih terlihat tidak patuh untuk menggunakan APD selama bekerja. Sehingga, pengawasan APD tidak mempengaruhi penggunaan APD tenaga kerja di departemen produksi PT X. Hal ini sejalan dengan penelitian yang dilakukan oleh Sulistyaningsih (2015) yang menyatakan bahwa meskipun pengawasan penggunaan APD telah dilakukan namun tenaga kerja tetap tidak menggunakan APD. ${ }^{9}$ Pengawasan bertujuan untuk menjamin terlaksananya rencana kebijakan, menertibkan koordinasi kegiatan, mencegah terjadinya pelanggaran, serta menjamin terwujudnya kepuasan atas jasa ataupun kegiatan pekerjaan yang dihasilkan. Pengawasan yang diadakan oleh PT X telah rutin dilakukan terutama mengenai penggunaan APD. Apabila tenaga kerja melakukan pelanggaran dengan tidak menggunakan APD, maka tenaga kerja tersebut akan mendapat sanksi. Sanksi penggunaan APD yang diterapkan di PT X kepada tenaga kerja adalah bertahap, yaitu pertama pemberian teguran lisan, kedua pembuatan surat pernyataan, dan ketiga pemberian surat peringatan satu sampai dengan tiga yang disertai pemotongan gaji 10\%. Akan tetapi, PT X tidak menerapkan sistem reward untuk tenaga kerja yang patuh menggunakan APD. Menurut Geller (2001), reward merupakan penguatan prositif yang diterima tenaga kerja ketika melakukan perilaku seperti yang diharapkan, sehingga tenaga kerja cenderung melakukan perilaku yang diharapkan ketika mengetahui konsekuensi yang akan muncul. ${ }^{14}$ Tenaga kerja lebih memiliki perasaan positif jika ia bekerja dengan tujuan untuk memperoleh sesuatu ketimbang menghindari kesalahan atau hukuman. Hasil penelitian ini bisa menjadi rekomendasi untuk perusahaan dalam mengadakan sistem reward dan sanksi secara seimbang. 


\section{SIMPULAN DAN SARAN}

\section{Simpulan}

Tenaga kerja di departemen produksi PT $\mathrm{X}$ rata-rata berumur 29 tahun dan masa kerja 8 tahun. Sebagian besar tenaga kerja di departemen produksi PT $\mathrm{X}$ patuh dalam menggunakan APD (60\%). Faktor yang mempengaruhi kepatuhan penggunaan APD adalah kenyamanan APD.

\section{Saran}

Perusahaan perlu menumbuhkan kesadaran tenaga kerja agar selalu menggunakan APD selama bekerja dengan melalui pendekatan individual oleh petugas $\mathrm{K} 3$ dan perusahaan perlu menerapkan kebijakan reward untuk penggunaan APD agar tenaga keja termotivasi dalam menggunakan APD.

\section{REFERENSI}

1. Siswanto. Alat Pelindung Diri. Surabaya: Departemen Tenaga Kerja. 1991.

2. Nugroho, S. Faktor yang Berhubungan dengan Kepatuhan dalam Menggunakan Alat Pelindung Diri pada Pekerja Proyek Konstuksi PT. Tatamulia Nusantara Indah. Skripsi. FKM Universitas Airlangga. 2015.

3. Iqbal, M. Gambaran Faktor-faktor Perilaku Penggunaan Alat Pelindung Diri (APD) pada Pekerja di Departemen Metalforming PT Dirgantara Indonesia (persero) Tahun 2014. Skripsi. FKIK Universitas Islam Negeri Syarif Hidayatullah. 2014.

4. Lagata, F.S. Gambaran Perilaku Penggunaan Alat Pelindung Diri (APD) pada Pekerja di Departemen Produksi PT Mauki Internasional Indonesia Makassar Tahun 2015. Skripsi. FKIK Universitas Islam Negeri Alauddin. 2015.
5. Arifin. Faktor-faktor yang Berhubungan dengan Kepatuhan Pekerja dalam Penggunaan APD di bagian Coal Yard PT. $X$ unit 3 \& 4 Kabupaten Jepara. Skripsi. FKM Universitas Diponegoro. 2013.

6. Lathif, A. Hubungan Beberapa Faktor dengan Kepatuhan Penggunaan Alat Pelindung Diri. Skripsi. FKM Universitas Airlangga. 2015.

7. Dhani, S. Faktor-faktor yang Berhubungan dengan Perilaku Penggunaan Alat Pelindung Diri pada Tenaga Kerja Produkdi PT. X, Sidoarjo. Skripsi. FKM Universitas Airlangga. 2015.

8. Notoatmodjo, S. Pendidikan dan Perilaku Kesehatan. Jakarta: PT. Rineka Cipta. 2003.

9. Sulistyaningsih, A. Faktor yang Berhubungan dengan Kepatuhan Penggunaan Alat Pelindung Diri. Skripsi. FKM Universitas Airlangga. 2015.

10. Syaaf. Analisis Perilaku Beresiko Pada Pekerja Unit Usaha Las Sektor Informal di kota X. Skripsi. FKM Universitas Indonesia. 2008.

11. Ramdayana. Faktor-faktor yang Berhubungan dengan Tingkat Kepatuhan Perawat terhadap Penggunaan APD di Ruang Rawat Inap Rumah Sakit Marinir Cilandak, Jakarta Selatan. Skripsi. Universitas Pembangunan Negeri Veteran Jakarta. 2009.

12. Peraturan Pemerintah No. 50 Tahun 2012 tentang Penerapan Sistem Manajemen Keselamatan dan Kesehatan Kerja (SMK3).

13. Undang-undang No. 1 Tahun 1970 tentang Keselamatan Kerja.

14. Geller. The Psychology of Safety Handbook. New York: Lewis Publisher. 2001.

15. Peraturan Menteri Tenaga Kerja Transmigrasi RI No. 8 Tahun 2010 tentang Alat Pelindung Diri. 